\title{
Perspectives on International Diversification: From 1991 to Pre-financial Crisis of 2008
}

\author{
Courtney Goffinet, Balasundram Maniam, and Hadley Leavell
}

\begin{abstract}
The advantage of globally diversifying one's investment portfolio to gain greater risk reduction has changed over the last fifty years. This empirical study analyzes the diversification benefits of the global equity market over almost two decades. The study compares three global regions in which the United States has a long-standing business relationship. The analyses are based on 1991-2008 data. The study compares the empirical results to previous studies which found that there has been a clear decrease in the advantage of international diversification since the 1950s and 1960s. This study found that the Western Hemisphere region produced the greatest amount of diversification advantage almost every time; that as the proportion invested internationally increased, the amount of the diversification advantage increased; and that the advantage of international diversification has, indeed, decreased drastically over the eighteen year period of this study and as compared to the previous studies. While there is still an advantage, albeit quite small, to globally diversifying one's financial portfolio, the degree of this advantage has clearly suffered from international integration. This study is important because it provides a current understanding and assessment of the risks and rewards inherent in global diversification while dispelling outdated concepts and facts through statistical analysis.
\end{abstract}

Index Terms-International diversification, risk reduction, coefficient correlation, global portfolio, international investment.

\section{INTRODUCTION}

Most people have heard the old adage, "Don't put all your eggs in one basket". If you invested all your money in one stock/industry/type of security, the risk of that one item defaulting is higher than if you invest in several stocks or industries or types of securities. This adage has been expanded to include the awareness that we should diversify our risk internationally as well. This study explores to what extent global diversification should influence one's investment decision-making process today.

The study considers three historical studies on the advantage of global diversification to offer a clearer comparison to this study's results. The study uses 18 years. This study considers three global regions and, within those regions, it considers three main countries and their respective

Manuscript received March 29, 2015; revised June 30, 2015.

C. Goffinet and B. Maniam are with Sam Houston State University, Huntsville, Texas, USA (e-mail: gba_bxm@shsu.edu; maniam@shsu.edu).

H. Leavell is with Sam Houston University, Huntsville, TX 77341, USA (e-mail: leavell@shsu.edu). stock markets. By examining the history of international diversification and by conducting an updated analysis, this study seeks to answer the broad question: Does global diversification still help strengthen domestic investors' portfolios, or is the world too integrated to glean a significant advantage? It is hoped that this study will provide new insights into this important topic given the ever changing global market place.

\section{LITERATURE REVIEW}

Reference [1] evaluated monthly stock data (ignoring dividends) from January 1956 to December 1995 to see if monetary policies affected stock prices and diversification. This study concluded that there was a high advantage to diversifying investment portfolios into international securities for the duration of their study. Their study is particularly relevant to this one in that it overlaps this study's time frame. Their study utilized the standard deviation as their measure for volatility and risk. Standard practice in risk analysis assumes that the higher the standard deviation, the more fluctuation (and volatility), and therefore the more financial risk is involved. This seems counterintuitive to the overall assessment that investors would benefit from international diversification (since the international standard deviations were significantly higher than the U.S.'s standard deviation) referred to in [1]. In an international setting, however, the higher standard deviation is somewhat offset by higher returns; hence, the adjusted risk return is higher.

Reference [2] discusses the changing attitudes and foregone opportunities concerning international investing. Reference [2] states, that in 1986, American investors viewed internationally diversifying their portfolios with a bit of a stigma, but by 1992 , the investors' attitudes had become more accepting. This perspective on the international investment environment is significant to this study because it establishes a reference point that, by the beginning of this study's time period, American investors were familiar with the concept of, and opportunities for, this type of diversification. Reference [2] explains that this financially beneficial prospect is rapidly becoming an exploited and diminishing possibility due to professional investors, essentially, taking full advantage of it: [2] demonstrates this advantage, providing the basic correlation coefficients between the developed and emerging foreign markets as compared to the U.S. market (using the Standard and Poor's 500 Composite Index, S\&P 500, as does this study). The results indicated that the developed foreign market had a 0.45 correlation coefficient to the U.S. market and the emerging foreign market had a 0.37 correlation coefficient. This information further clarifies the investment 
opportunity for investors and further establishes the reference point relevant to this study.

Reference [3] used the correlation coefficient and, thus, is more comparable with this study since the measurement of risk is the same. Also, the study mentioned in [3] examines many of the same countries as this study. Reference [3] conducted his examination over a 24-year period, from 1971 to 1994 . These data are important for comparison later with our calculations. The highest correlation in [3] is 0.68 which is the correlation of the U.S. and Canadian markets. This is a higher correlation because these markets are obviously connected by land and economic factors (1996). The important figures for the purposes of this study are the correlation coefficients for the countries we have chosen to study as related to the United States referred to in [3].

\section{DATA AND Methodology}

When using correlation coefficients to analyze risk diversification, note that an inverse relationship exists. In other words, when the correlation coefficient increases, the advantage of diversification decreases, and when the correlation coefficient decreases, the diversification advantage increases. So investors who want to maximize their global diversification advantage will invest in those stocks, industries, security types, or countries with the lowest correlation coefficients to their base stock/industry/security type/country.

As seen in historical studies, the advantage of global diversification has been changing over the past fifty years and needs to be re-assessed so current investors can make the most well-informed decision about investing internationally. This study will explore just those questions: whether or not the markets have become more integrated and subsequently have led to higher correlation coefficients (which would suggest lower diversification advantage); and by how much the correlation across stock markets has trended upward.

This study's purpose is to determine how the advantage of global diversification has changed over time, region, and quantity of diversification in the equities market. For example, in the case of quantity diversification, what should be the portfolio mix between domestic and global investment? The study compares three global regions that with which the United States has an established business relationship: the European region, the Asian region, and the Western Hemisphere region (excluding the United States of course). Three countries were chosen within each region, not only because each has had a long-standing trading/investing relationship with the United States, but also due to other factors (such as economic development and whether they had an established stock market index). For the European region, the selected countries were the United Kingdom, Germany, and Switzerland. The Asian region consists of China, Hong Kong, and Japan. Finally, the Western Hemisphere region comprises Canada, Mexico, and Brazil. The study employs time analysis (how the diversification advantage has changed from January 1, 1991, to December 31, 2008), and how it has changed when that time period was broken into three equal sections), percentage analysis (how the diversification changed depending on the percent of investment in global or regional securities), and region/time analysis (to see if one region significantly declined in diversification more or less than the others as well as over time).

This study makes several assumptions to control the variables (as best as possible) to test only the desired characteristics. The study first assumes that the investor is passive, meaning that the investor does not choose stocks, industry categories, or markets but invests in an entire index (which should be highly diversified by its very nature) and takes no steps to time their investments for an optimal return [4]. This method is interpreted as the "better" method if the Efficient Market Theory is true. The study also assumes that the investment portfolios consist only of stocks and, thus, ignores any dividends received. Due to the constraints of this study and the availability of accurate data, the study cannot diversify the portfolios by type of security.

The stock data was obtained from Datastream, which is a database of various types of financial information [5]. This program gathered the stock data, not only on a daily basis for the entire study period, but also already converted into U.S. dollars. The program also gave the currency exchange rates for each day during the period, which were used to convert the raw data for each country (in their currency) into U.S. dollars. This verified that the information already converted into U.S. dollars was accurate. Therefore the problem of currency exchange risk should be eliminated, thereby making the study more accurate.

Another important assumption is that the "base portfolio" consists of zero global or regional diversification. Therefore, the base portfolio contains a $100 \%$ investment in the U.S. S\&P 500. The S\&P 500 was chosen because it is used by the U.S. government as a leading economic indicator [6]. Like the S\&P 500, the other indices were chosen if they were found to be leading economic indicators for their respective countries and/or because they occupy such a majority of the equities market (over 70\%) that they are considered "market indicators" for their respective countries. The other indices chosen were:

- United Kingdom - the Financial Times/London Stock Exchange 100 (FTSE 100) [7];

- Germany - the Deutscher Aktein Index 30 (DAX 30) [8] [9];

- $\quad$ Switzerland - the Swiss Market Index (SMI) [10];

- China - the Shanghai SE Composite (SSEC) [11];

- Hong Kong - the Hang Seng Index [12];

- Japan - the Tokyo Stock Price Index (TOPIX) [13];

- Canada-the Toronto Stock Exchange's S\&P/TSX Composite (S\&P/TSX) [14];

- Mexico - the BOLSA, which is Spanish for "stock exchange" [15] and

- Brazil-the Bolsa de Valores de Sao Paulo Index (BOVESPA) [16].

- The DAX 30 and the SMI are two examples of indices used because they hold over $70 \%$ of the equities' market in their countries (90\% and $85 \%$, respectively).

The time frame comprising the study was 18 years. The time frame was first analyzed over the entire period, then analyzed to note the changes if it were broken into three equal 
intervals: from January 1, 1991, to December 31, 1996; from January 1, 1997, to December 31, 2002; and from January 1, 2003, to December 31, 2008.

The data were statistically analyzed using StataSE 9. The data as a whole was analyzed to see if the information was "normal" or "irregular." The program also generated the correlation coefficients, graphs, and tables that were then analyzed to examine the many hypotheses. There are a couple of proven methods to measure an investment's level of risk. Whereas the standard deviation measures the volatility of an investment, it does not detail its relation to another investment option. Thus this study utilizes the correlation coefficients to establish how risky the comparison portfolios are to the base portfolio. The correlation coefficient ranges in value from -1.00 to +1.00 . The closer it is to -1.00 , the higher the benefit of diversification; similarly the closer it is to +1.00 , the smaller the benefit of diversification. In this way, the study establishes how closely the portfolios move with each other. If investors are to truly diversify their investment opportunities, then they will want to devote resources to whichever portfolio combination generates the lowest correlation coefficient for each analysis situation.

\section{HYPOTHESES}

The study tests two hypotheses to fully analyze and explore the use of foreign investments to diversify an investor's portfolio - not by industry or type of security, but by diversifying through investment location. The hypotheses are broadly classified as follows:

- Hypothesis 1: The benefit of diversification increases as the proportion of regional foreign investment increases over the entire observation period.

- Hypothesis 2: The benefit of diversification decreases over time in a given region for the portfolio mix of $25 \%$ domestic/75\% regional investment.

\section{EMPIRICAL RESULTS}

The degree to which one market moves in relationship to another is called "market correlation" [3]. The study utilizes this measure because it is a simple yet powerful approach to analyze risk diversification. The study's four basic hypotheses (listed above) were further broken down into sub-hypotheses to answer each of the broader questions.

\section{A. Hypothesis 1}

Hypothesis 1 must be broken down into three sub-hypotheses to test if the benefit of diversification is constant across regions for each given portfolio mix over the entire observation period. For this part of the study, the portfolios are comprised of a percentage invested in the U.S. domestic market (for which this study, again, has chosen to use the S\&P 500 as the base) and a percentage invested equally across the region's three foreign market indices. The sub-hypotheses are:

- Hypothesis 1A: The benefit of diversification is constant across regions for the given portfolio mix of $75 \%$ invested in the domestic index and $25 \%$ invested in the regional indices.

- Hypothesis 1B: The benefit of diversification is constant across regions for the given portfolio mix of $50 \%$ invested in the domestic index and 50\% invested in the regional indices.

- Hypothesis 1C: The benefit of diversification is constant across regions for the given portfolio mix of $25 \%$ invested in the domestic index and $75 \%$ invested in the regional indices.

For Hypothesis 1A, Table IA shows the correlation coefficients for all three regional portfolios in relation to the base portfolio. In this case, all the portfolios (except the base portfolio, which is $100 \%$ invested in the domestic index) have a compilation of $75 \%$ domestic investment and $25 \%$ regional investment. In relation to the U.S. market, the European region has a 0.9964 correlation coefficient; the Asian region has a 0.9747 correlation coefficient; and the Western Hemisphere region has a 0.9066 correlation coefficient. Here we can clearly see that the Western Hemisphere regional portfolio has the lowest correlation coefficient compared to the other two regions. This clearly indicates that at this portfolio mix, the Western Hemisphere regional portfolio has a significantly lower correlation coefficient compared to the other two regions. For the purposes of this study, we deemed "significantly lower" as greater than a \pm 0.0500 difference from the base portfolio correlation coefficient.

TABLE IA: PORTFOLIO MIX: 75\% U.S./25\% REGION

\begin{tabular}{ll} 
TABLE IA: PORTFOLIO MIX: $75 \%$ U.S./25\% REGION \\
\hline US $100 \%$ & US $100 \%$ \\
US 75\% / Europe 25\% & 1.0000 \\
US 75\% / Asia 25\% & 0.9964 \\
US 75\% / Western Hemisphere 25\% & 0.9747 \\
\hline
\end{tabular}

In Table IB the portfolios consist of 50\% investment in the domestic index and 50\% investment in the regional indices. We see that the European portfolio holds a 0.9841 correlation coefficient, the Asian portfolio has a 0.9180 correlation coefficient, and the Western Hemisphere, again, has the lowest correlation coefficient at 0.7950 . This time, both the Asian and Western Hemisphere regions have relatively low correlation coefficients, although the Western Hemisphere is much lower.

\begin{tabular}{lc} 
TABLE IB: PORTFOLIO MIX: 50\% U.S./50\% REGION \\
\hline & US 100\% \\
US 100\% & 1.0000 \\
US 50\% / Europe 50\% & 0.9841 \\
US 50\% / Asia 50\% & 0.9180 \\
US 50\% / Western Hemisphere 50\% & 0.7950 \\
\hline \multicolumn{3}{c}{ TABLE IC: PORTFOLIO MIX: 25\% U.S./75\% REGION } \\
\hline \multicolumn{3}{l}{ US 100\% } \\
US 100\% & 1.0000 \\
US 25\% / Europe 75\% & 0.9606 \\
US 25\% / Asia 75\% & 0.8528 \\
US 25\% / Western Hemisphere 75\% & 0.7180 \\
\hline
\end{tabular}

Finally in the last case, we see that for Hypothesis $1 \mathrm{C}$, in Table IC, the regional portfolios have a similar trend as before; that is, that the Western Hemisphere portfolio has a lower correlation coefficient than the other two, with the Asian portfolio in the second position. It should be noted that 
at this mix, the Western Hemisphere portfolio exhibits the most optimal diversification benefit of all of the three possible portfolio mixes. Its correlation coefficient is only 0.7180 , which is superior to any other mix. Also, it should be noted that the Asian and European correlation coefficients are lower at this mix than the other two mixes. It is safe to say that both the Asian and Western Hemisphere portfolios exhibit a significant investment opportunity to potential investors.

Overall for Hypothesis 1, there are several conclusions that may be drawn (see Tables IA-IC). First, the greater the invested amount is in the foreign region, as opposed to the domestic investment, the more likely to have a greater number of portfolios that produce lower correlation coefficients, meaning that they possess greater diversification benefits. The other interesting finding is that no matter what portfolio mix is utilized, the Western Hemisphere always performed better than the other regions (from a lower correlation coefficient standpoint). This implies that the Western Hemisphere has the highest diversification advantage (since the correlation coefficient and diversification advantage are inversely related). This is important information for an investor employing foreign investing to diversify (and, subsequently, reduce the risk of) their entire investment portfolio.

TABLE II: DIVERSIFICATION BENEFITS OVER TIME PERIODS

\begin{tabular}{lllll}
\hline & $1991-96$ & $1997-02$ & $2003-08$ & Entire Period \\
& US 100\% & US 100\% & US 100\% & US 100\% \\
\hline US 100\% & 1.0000 & 1.0000 & 1.0000 & 1.0000 \\
US 25\%/Europe 75\% & 0.9818 & 0.9201 & 0.9638 & 0.9606 \\
US 25\%/Asia 75\% & 0.8729 & 0.6910 & 0.8558 & 0.8528 \\
US 25\%/Western & 0.8851 & 0.5200 & 0.8073 & 0.7180 \\
Hemisphere 75\% & & & & \\
\hline
\end{tabular}

Also, Hypothesis 1 conveys that the greatest regional mix yields the lowest correlation coefficient for any region and/or regional mix in the Western Hemisphere. This implies that either we have somewhat ignored the investment opportunity in this region or global investors have placed too much emphasis in the other regions, resulting in their correlation coefficients increasing over time. These results are not surprising, however, because over the last twenty years, investors have invested heavily in the European and Asian regions while avoiding the Western Hemisphere.

\section{B. Hypothesis 2}

This hypothesis looks at the benefit of diversification over time for a given region, holding the portfolio mix steady at the proportion of $25 \%$ invested in the domestic market and $75 \%$ invested in the region's indices. [Note: Hypothesis 2 only considers one portfolio mix because Hypothesis 1 found that the greatest amount of regional investment resulted in the most diversification advantage. Therefore, the other two portfolio mixes were omitted for this hypothesis.] The rationale for utilizing this portfolio mix only is that many studies have consistently indicated that this combination yields the greatest benefit concerning diversification. In this hypothesis, we evaluate the benefit of diversification by looking at the portfolio containing $25 \%$ domestic investment and $75 \%$ invested equally into the three indices in the European region and analyze the changes in the correlation coefficient for the time period between January 1, 1991, and
December 31, 1996; between January 1, 1997, and December 31, 2002; between January 1, 2003, and December 31, 2008; as well as for the entire observation period (from January 1, 1991, to December 31, 2008). This process is then repeated for the other regions. Table II provides these results.

In Table II, the research reveals a downward trend for all the portfolios from the first period (from January 1, 1991, to December 31, 1996) to the second period (from January 1, 1997, to December 31, 2002), then an upward trend from the second time segment to the third (from January 1, 2003, to December 31, 2008). Interestingly, the third period's correlation coefficient values are very close to the entire period's values (excepting the Western Hemisphere which was still significant).

The European region changed the least from period to period, but still had the least amount of diversification advantage at all times. This suggests that the European region is already well integrated with the U.S. market and, hence, the benefit of diversifying one's portfolio into this region is minimal. The Asian and Western Hemisphere regions, however, both had tremendous decreases in their correlation coefficients from the first period to the second (a drop of 0.1819 for the Asian region and a drop of 0.3651 for the Western Hemisphere). Both dropped by more than eighteen points, an extremely significant amount. Unfortunately, both the Asian and Western Hemisphere regions also had incredible increases in their correlation coefficients from the second to the third periods, bringing both very close to their original values for the first period. This would only imply an initial diversification benefit increase, but after further integration with these markets, the benefit somewhat diminished.

Several factors could be responsible, singularly or collectively, for these wide swings, including but not limited to economic, political, or climatic conditions, none of which will be researched extensively in this study. We can conclude a few judgments concerning Hypothesis 2 though, which are that the Western Hemisphere, again, consistently (except for the period from 1991 through 1996, when Asia is) ranks as the lowest correlation coefficient across the board, which again conveys that this region has the most diversification advantage of all three regions; during the second time frame, all three regions were significantly different than the previous time period; and lastly both the Asian and Western Hemisphere regions were significantly changed from each previous period and significantly lower in their correlation coefficients in each time period for this hypothesis.

\section{CONCLUSIONS AND SUGGESTIONS}

The idea of benefitting by globally diversifying one's investments needs to be re-evaluated from time to time to determine the current level of the advantage. This research finds the greatest advantage in global diversification by diversifying with the highest proportion devoted to global or regional investment (75\% globally or regionally invested and $25 \%$ domestically invested) no matter how the data is analyzed. The study did not find the point at which the advantage tapered off with more investment abroad, and though we still believe such a point exists, we were limited to 
how many different intervals we could assess at this time.

Hypothesis 1 finds that, if the investor further selects their diversification by region, then they will, every time, do better to invest in the Western Hemisphere region. The possible explanations for this additional advantage could be that Americans have ignored investment opportunities in this region and/or that they have placed too much emphasis on the other two regions. This somewhat violates our assumption that the investor is passive, since a truly passive global investor would put their global funds into a global index and wouldn't have invested in specific regions or countries.

Hypothesis 2 reveals that the European region is the most stable over time but also has the least advantage consistently. The Western Hemisphere always produced the most advantage of the three regions over time (of course, except during the period from 1991 through 1996). This hypothesis also demonstrates that during the second time frame, all the regions enjoyed a significant drop in their correlation coefficients, and, thus, that the second time frame held the most advantage for international investors. Unfortunately, this hypothesis also shows that all three regions increase greatly from the second to the third period as well, bringing all the regions close to their original correlation coefficients from the first time period.

Although there is still an advantage to globally diversifying one's portfolio to not run the risk of "putting all your eggs in one basket," this advantage has greatly decreased. Conover, Jensen, and Johnson's study is not as easy to compare to this study, but they clearly felt that American investors could benefit from international diversification [1].

While this study took a portfolio approach to find the correlation coefficients - unlike [3], which evaluated different countries singularly against themselves as the only base - we can still see a vast difference from the findings in [3] and this study's tables. During the study referred to in [3] (from 1971 to 1994), the European region's average correlation coefficient (against the United States) was 0.4467 (based on the United Kingdom having a 0.51 correlation coefficient, Germany having a 0.36 correlation coefficient, and Switzerland having a 0.47 correlation coefficient). Similarly, the Asian region's average correlation coefficient was 0.2800 (this was based only on Hong Kong and Japan's values since [3] did not study China; this calculation is derived, therefore, from the simple average of the indices of Hong Kong and Japan divided by two), and the Western Hemisphere's average was 0.6800 (based solely on Canada's value because [3] did not study Mexico and Brazil). Even when we compare the historical amounts from the study mentioned in [3] to the best regional advantage (achieved with the $25 \%$ domestic/75\% regional investment), the values produced are 0.9606 for the European region, 0.8528 for the Asian region, and 0.7180 for the Western Hemisphere region. While the comparisons have to be taken in context (since they are not true apple-to-apple comparisons), we can still clearly see that the values today are significantly different than the averages once achieved by these regions.

We can also make a general comparison to the simple average of the correlation coefficients of the countries studied in [3] to our global correlations. Once again, we take the simple average of all of the correlation coefficients (only dividing by six) and generate a 0.4300 average correlation coefficient from the study mentioned in [3]. This can be compared to the entire period, equally diversified portfolio correlation coefficient of 0.8477 (we again used the greatest portfolio mix advantage of $25 \%$ domestic/75\% global) [3]. While, again, this is not a perfect comparison, the study still shows a clear, vast decrease in the advantage of globally diversifying one's investment portfolio.

Reference [3] predicted that the removal of obstacles to international investments, combined with integration in the political, economic, and financial arenas would directly impact international market linkages. This study proves that his prediction has become true in the past two decades. The world's equities markets have become more integrated and, thus, the advantage of global diversification has declined over the years. Consistent with this study's findings, there is clearly still an advantage to globally diversifying one's portfolio, but we feel that the international investor will make a better-informed investment and, consequently, have more attainable and realistic expectations for their overall investment portfolio.

\section{REFERENCES}

[1] M. Conover, G. Jensen, and R. Johnson, "Monetary conditions and international investing," Financial Analysts Journal, vol. 55, no. 4, pp. 38-48, 1999

[2] J. W. Wilcox, "Global investing in emerging markets," Financial Analysts Journal, vol. 48, no. 1, pp. 15-19, 1992.

[3] B. Solnik, International Investments, 3rd ed. Reading, Massachusetts: Addison-Wesley Publishing Company, 1996.

[4] Z. Bodie, A. Kane, and A. Marcu, Essentials of Investments, 7th ed. Boston, Massachusetts: McGraw-Hill/Irwin, 2008.

[5] Thomson Financial, Leading Economic Indicators, Stock Indices, Daily Stock Data in USD, Time Frame: 1991 - 2008, 2008.

[6] The Conference Board (US), "The conference board leading economic index (LEI) for the United States and related composite economic indexes for February 2010," Global Business Cycle Indicators Member Website - The Conference Board, March 2010.

[7] The Conference Board (UK), "The conference board leading economic index (LEI) for the United Kingdom and related composite economic indexes for January 2010," Business Cycle Indicators Member Website - The Conference Board, March 2010.

[8] The Conference Board, Germany, "The conference board leading economic index (LEI) for Germany and related composite economic indexes for January 2010," Global Business Cycle Indicators Member Website — The Conference Board, March 2010.

[9] Deutsche Bundesbank Eurosystem, "Time series WU3140: DAX price index," Deutsche Bundesbank, March 2010.

[10] SIX Swiss Exchange, "SMI — the Blue-Chip Index," SIX Swiss Exchange, March 2010.

[11] M. Markowski. (August 2009). Two key indicators that stock market timers should be following. [Online]. Available: http://www.onlinefinancialsector.com/Articles.asp?ID=485

[12] W. S. Hung. (February 2003). Joint OECD/ESCAP Workshop on Composite Leading Indicators and Business Tendency Surveys. United Nations Economic and Social Commission for Asia and the Pacific [Online]. Available: http://www.unescap.org/STAT/meet/cli_bts/cli_bts_hongkong1.pdf

[13] The Conference Board (Japan), "The conference board leading economic index (LEI) for Japan and related composite economic indexes for January 2010," Global Business Cycle Indicators Member Website - The Conference Board, March 2010.

[14] Statistics Canada, "Leading indicators," Statistics Canada, March 2010.

[15] The Conference Board Mexico, "The conference board leading economic index (LEI) for Mexico and related composite economic indexes for January 2010," Global Business Cycle Indicators Member Website - The Conference Board, March 2010. 
[16] Banco Central do Brasil, "Economic Indicators," Banco Central do Brasil, March 2010.

Courtney Goffinet was a honors student and she obtained her degree from Sam Houston State University. Her research interests include economics, and international finance. She has work on several articles in these areas.

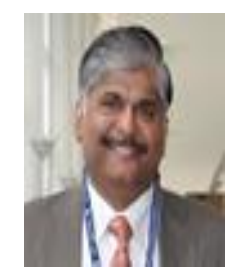

Balasundram Maniam is a distinguished regents' professor of finance and a Minnie Stevens Piper professor at Sam Houston State University, Texas, USA. He obtained his Ph.D. degree from University of Mississippi in 1992. He has published over 150 peer-reviewed journals and presented over 250 international and national conferences. He was also the recipient of Excellence in Research and Excellence in
Teaching awards at Sam Houston State University in 2003 and 2008 respectively. He also serves as an editor and co-editor of journals and serves in editorial boards of several journals.

Hadley Leavell is a professor of finance at Sam Houston State University, Texas, USA. He obtained his DBA degree from Louisiana Tech University. He has published many peer-reviewed journals in the area of finance and international business. He also has presented in many national and international conferences. He also serves in the editorial board of the Journal of International Business Research. 